\title{
İlaç Formülasyonu Geliştirilmesinde Deney Tasarımı (DoE) Seçimi ve Kullanımı
}

\author{
Önder Demir, Buket Aksu, Yıldız Özsoy
}

ÖZ

Son yıllarda ilaç formülasyonu geliştirilmesinde deney tasarımı (DoE) kullanımı artmış olmasına rağmen hala yeterli seviyede değildir. Özellikle katı ve yarı-katı dozaj formları gibi birçok bileşeni olan ve çıktılara etkisi bilinmeyen birçok proses parametresinin bulunduğu formülasyonlarda kullanılmasının ne kadar yararlı olduğu bilinmektedir. Ancak formülasyon geliştirmede deneme-yanılma gibi eski yaklaşımlar yerine DoE kullanılması ne kadar önemli ise, bu DoE’nin doğru kullanımı ve seçimi de bir o kadar önemlidir. Doğru seçilmeyen bir DoE tipi veya uygun olmayacak şekilde yapılan deneme ve ölçümler, sadece boşa kaynak ve zaman harcanması ile sonuçlanmaz, çoğu zaman kafa karıştırıcı veya yanıltıcı veriler de üretir. Bu derlemede DoE, uygun DoE tipinin seçimi, istatiksel eleme ile faktör sayısının düşürülmesi ve yanıt yüzeyi modellemesi (RSM) ile ilaç formülasyonlarının optimizasyonu hakkında özet bilgi verilmesi amaçlanmış olup, bu yöntemlerin ilaç formülasyonu geliştirmedeki uygulamalarından da kısaca bahsedilmiştir. Doğru DoE tipinin seçilerek uygulanması sayesinde; gerçekleştirilen az sayıdaki denemelerden çok fazla kaliteli bilgi (matematiksel modeller) üretilebilir. Bu sayede geliştirme süresi ve maliyeti ciddi oranda azaltılabilir. Ayrıca geliştirilen ürün, değişkenliklere karşı hassas olmayan sağlam bir prosese sahip olabilir.

Anahtar Kelimeler: Deney tasarımı, formülasyon geliștirme, ilaç, yanıt yüzeyi modelleme, optimizasyon.
Önder Demir

Mustafa Nevzat İlaç Sanayi İlaç Üretim Tesisi, Yenibosna Merkez Mah. Sanayi Cad. No:13, 34196 Bahçelievler / İstanbul

Buket Aksu

Kemerburgaz Üniversitesi, Eczacılık Fakültesi, Farmasötik Teknoloji Anabilim Dal, İstanbul

Yıldız Özsoy

İstanbul Üniversitesi, Eczactlk Fakültesi, Farmasötik Teknoloji Anabilim Dal,, Istanbul

\section{Sorumlu Yazar:}

Önder Demir

e-mail: ondemir601@hotmail.com,onder.demir@mn.com.tr

Submitted / Gönderilme: 12.08.2016 Revised/ Düzeltme: 15.11.2016

Accepted / Kabul: 17.11.2016

\section{GİRIŞ}

Deney Tasarımı (Design of Experiments, DoE), toplanan deneme verilerinden en yüksek miktarda bilginin, etkili bir şekilde elde edilebilmesi için yapılacak olan denemeleri planlama stratejisi olarak tanımlanır (1). Farklı faktörler (bağımsız değişken, girdi, proses parametresi, formülasyon bileşeni vb.) ile onların etkilediği cevap değişkenleri (bağımlı değişken, yanıt değişkeni, çıktı, ürün kalite özelliği vb.) arasındaki ilişkiyi belirlemek için kullanılan yapısal ve organize bir yöntemdir (2).

DoE'de ana fikir; planlanmış bir deneme setinde tüm ilgili faktörlerin eş zamanlı olarak değiştirilmesi ve bu değiştirilen faktörlere karşı elde edilen sonuçlar arasında bağıntı kuran bir matematiksel model elde edilmesidir (3). Bu matematiksel modeller ile sonuçlar yorumlanabilir, tahminde bulunabilinir ve optimizasyon yapılarak tasarım aralığı (design space) belirlenebilir. Sistematik DoE yaklaşımlarının, etkili bir formülasyonu garantilemek için daha az deneysel çalışma, 
daha kolay problem tanımlama ve önleme, herhangi bir etken madde-yardımcı madde etkileşimini ve ürün performansını gösterme, ölçek büyütme aşamasında iyi sonuç eldesi için proses optimizasyonu gibi avantajları vardır (4).

Ölçülebilir girdi ve çıktıları olan farmasötik sistem veya prosesler için DoE, kritik faktörlerin tanımlanması, optimum faktör seviyelerinin belirlenmesi, formülasyon seçim çalışması, problem çözümü, parametre tasarımı ve proses sağlamlığı gibi çalışmalarda, en uygun olanın seçiminde rehberlik etmede kullanılabilir (5-7).

İdeal olarak bir dozaj formu tasarımı, en sonunda istenen ürüne dönüşecek olan hammaddelerin fizikokimyasal ve mekanik dönüşümlerinin yapısal olarak anlaşılmasına dayanmalıdır. Ancak ilaç bileşenlerinin çeşitliliği ve karmaşıklığı, ilaç üretiminde gerçekleştirilen bir dizi birim operasyonlarla da birleştiğinde, genellikle tam olarak anlaşılma sağlanamaz. Buna karşılık, sistematik bir yaklaşım ile DoE uygulanması sayesinde; ürün ve üretim prosesi derinlemesine anlaşılabilir ve bu şekilde girdilerin değişkenliği ile ürün kalitesine karşı olabilecek diğer riskleri de dikkate alan bir geliştirme yaklaşımı sağlanabilir (8).

Hedeflenen ürün kalitesinin sağlanmasını garanti altına alan tasarım aralığını elde etmek için girdi değişkenlerinin çok boyutlu etkileşimini sağlayan DoE'nin kullanımı, her geçen gün daha çok önem kazanmaktadır. Tasarım aralığı, kritik madde özellikleri (Critical Material Attributes, CMA) ve kritik proses parametrelerinin (Critical Process Parameters, CPP), en uygun aralıktaki seviyelerinden oluşur (9). DoE ve modelleme sayesinde tasarım aralığı belirlenmiş bir üründe, girdiler tasarım aralığında belirtilen seviye aralıklarında kaldığ 1 sürece, ürün kalite çıktıları her zaman istenen aralıkta olacaktır.

$\mathrm{Bu}$ derlemede DoE, uygun DoE tipinin seçimi, istatiksel eleme (screening) ile faktör sayısının düşürülmesi ve yanıt yüzeyi modellemesi (RSM) ile ilaç formülasyonlarının optimizasyonu hakkında özet bilgi verilmesi amaçlanmış olup, bu yöntemlerin ilaç formülasyonu geliştirmedeki uygulamalarından da kısaca bahsedilmiştir.

\section{PROBLEMIN TANIMI}

Bir DoE yazılımı ile tasarım tablosu oluşturmak, zor bir iş olmamasına rağmen girdilere karşı çıktıların kesin ve doğru ölçümlerde olması, denemeler sırasında sabit ve/veya ürün çıktılarına etkisi olmadığı varsayılan dış faktörlerin gözlemlenmesi ve kontrol altında tutulması, küçümsenecek bir konu değildir. Şuna da dikkat çekmek gerekir ki; doğru seçilmeyen bir DoE tipi veya uygun olmayacak şekilde yapılan deneme ve ölçümler, sadece boşa kaynak ve zaman harcanması ile sonuçlanmaz, çoğu zaman kafa karıştırıcı veya yanıltıcı veriler de üretir. İlaç dozaj formu geliştirilmesi sırasında kullanılacak olan deney tasarımlarıyla ilgili bazı yaygın sorunlar aşağıdaki gibi özetlenebilir.

- Bağımsız girdi değişkenleri ile bağımlı çıktı değişkenleri arasındaki ilişkiyi, doğru yansıtamayacak veya yeterli bilgi veremeyecek modeller üreten yanlış tipte bir DoE'nin seçilmesi.

- Uygun olmayan tasarım değişkenlerinin seçilmesi (ürün kalitesini temsil etmeyen yanlış çıktıların seçilmesi, çıktılara etkisi yüksek olmayan yanlış girdi değişkenlerinin ve/veya uygun olmayan aralıklarının seçilmesi).

- Sabit ve/veya ürün çıktılarına etkisi olmadığı varsayılan farklı faktörlerin etkisinden habersiz bir şekilde kontrolsüz olarak denemelerin gerçekleştirilmesi (Her bir denemede farklı deneyim ve eğitimde personelin çalışması, farklı ortam sıcaklığı ve nemi, farklı ekipman kullanımı vs.).

- Uygunsuz şekilde ölçümler alınması, yetersiz büyüklükte numune boyutları alınması veya analitik ölçüm cihazlarındaki Sinyal-Gürültü Oranının (Signal-Noise Rate, SNR) yeterince anlaşılamamasından kaynaklanan güvenilir veya kesin olmayan yetersiz verilerin üretilmesi.

Bir deney tasarımı oluşturulurken, öncelikle çalışmanın temel bilgilerini elde etmek çok önemlidir. Mümkün olan en az sayıda denemenin, doğru bir modelleme ile çok bilgi üretebilmesi için aşağıda belirtilen adımların yapılması da çok önemlidir (8):

1. Ürün kalitesini sağlamak için ölçülecek olan kritik kalite özellikleri, mevcut tecrübe ve bilgi ile risk değerlendirme yöntemine dayanılarak belirlenir ve bu değişkenlerin ölçüm kesinliğinin sağlanabildiğinden emin olunur,

2. Bu kritik kalite özelliklerine etkisi olabilecek muhtemel faktörler, mevcut tecrübe ve bilgiye dayanılarak listelenir ve değerlendirilir,

3. Bu muhtemel faktörler arasından tasarıma dahil edilecek olan kritik faktörler (CPP ve/veya CMA), bunların seviye aralıkları ve sabit olacak olan değişkenler, risk değerlendirme veya istatiksel eleme gibi yöntemlerle belirlenir,

4. Mevcut istatiksel deney tasarımları arasından ölçümlerin kesinliği, tasarım değişkenlerinin sayısı, tipi ve çalışmanın amacı ile uyumlu olan birisi seçilir. 


\section{3. İSTATIKKSEL ELEME TASARIMLARI}

İstatiksel eleme, değişmesi halinde çıktıları da büyük oranda değiştiren CPP ve CMA gibi kritik faktörlerin ve olası seviyelerinin belirlenmesinde kullanılır. Formülasyonun optimizasyonuna geçmeden önce deneysel çalışmadaki ilk aşamadır. İstatiksel elemede, sadece ana faktör etkilerini içeren doğrusal modeller veya ikili etkileşimleri de içeren doğrusal modeller gibi basit modeller kullanılır. Bu şekilde mümkün olan en az sayıda deneme ile çıktılara en çok etkisi olan faktörler belirlenip, etkisi az olan ya da istatiksel olarak anlamlı etkisi olmayan faktörler elenebilmektedir. Ayrıca faktör sayısının azaltılmasıyla, daha az denemenin olduğu bir optimizasyon tasarımına geçilebilmektedir.

Bir DoE’nin seçimi, her zaman yapılacak olan araştırmanın amacı, araştırılacak faktör sayısı ve tipine dayanmalıdır. Örneğin amaç, sadece faktör sayısını düşürmek ve çıtıllar üzerinde etkisi en yüksek olan birkaç faktörü bulmak şeklinde ise, ve araştırılacak çok fazla faktör varsa, en az sayıda deneme yapılmasina imkan veren, ancak sadece ana faktör etkilerini doğrusal modeller kurarak değerlendiren istatiksel eleme tasarımları seçilebilir. İstatiksel eleme amacıyla gerçekleştirilen DoE tipleri aşağıda sunulmuştur.

\section{1. İki seviyeli tam faktöriyel tasarım $\left(2^{\mathrm{k}}\right)$}

Bu tasarımlarda, her bir faktörde düşük (-) ve yüksek (+) şeklinde iki seviye bulunur. Yapılacak olan denemelerde faktör seviyelerinin tüm olası sıralanış biçimi (kombinasyonları) bulunur. k sayıda faktör için yapılacak olan deneme sayısı $2^{\mathrm{k}}$ şeklinde olur. Tam faktöriyel tasarımlar ortogonal (dengeli) olduğundan modelin tahmin ettiği bir faktör etkisi, tüm diğer faktörlerin etkisinden bağımsızdır. Faktör eleme amacıyla kullanımında, ilaç sektörü için fazla deneme sayısı oluşturduğundan nispeten daha az tercih edilir. Ancak formülasyonların optimizasyonu amacıyla kullanımı yaygın bir tasarımdır $(10,11)$.

Kuru granülasyon yöntemi ile üretilen, ağızda dağılan tablet formundaki bir ürünün formülasyonunda dağıtıcı yüzdesi ve prosesinde de silindirik sıkıştırma basıncı ile tablet baskı kuvveti şeklinde üç adet kritik faktör olduğunu düşünelim. $\mathrm{Bu}$ üç faktörün, düşük (-) ve yüksek (+) seviyelerinin değiştirilmesiyle elde edilen olası tüm sıralanış biçimi Şekil 1'de gösterilmiştir. Şekildeki küpte gösterilen herbir nokta, bir denemedir. $X_{1}, X_{2}$ ve $X_{3}$ olarak gösterilen iki seviyeli üç adet faktör; $2^{3}=8$ deneme yapılmasını gerektiren tam faktöriyel bir tasarım oluşturur (12).

\subsection{Kısmi faktöriyel tasarım $\left(2^{k-p}\right)$}

$\mathrm{Bu}$ tasarım, iki seviyeli tam faktöriyel tasarımın dengeli bir şekilde oluşturulmuş bir bölümüdür (alt kümesidir). Çözünürlük III, IV ve V şeklinde tasarlanabilir. Çözünürlük III, ana faktör etkileri ile ikili faktör etkileşimlerini karıştırarak deney tasarlar. Çözünürlük IV, ikili faktör etkileşimlerini birbirleriyle karıştırarak deney tasarlar. Çözünürlük V'de ise, ana faktör etkileri ile ikili faktör etkileşimleri karışmamış haldedir. Çözünürlük, her bir faktör aralığının (araştırılan bölgenin) bölüneceği farklı bölüm (blok) sayısıdır ve yorumlanan sonuçların kesinliğinin göstergesidir. Çözünürlük değeri arttıkça model kesinliği artar, ancak yapılacak deneme sayısı da artar. Çözünürlük III ve IV’te sadece doğrusal modeller oluşturulabilirken, çözünürlük V'de etkileşim modeli oluşturulabilir $(1,13)$.

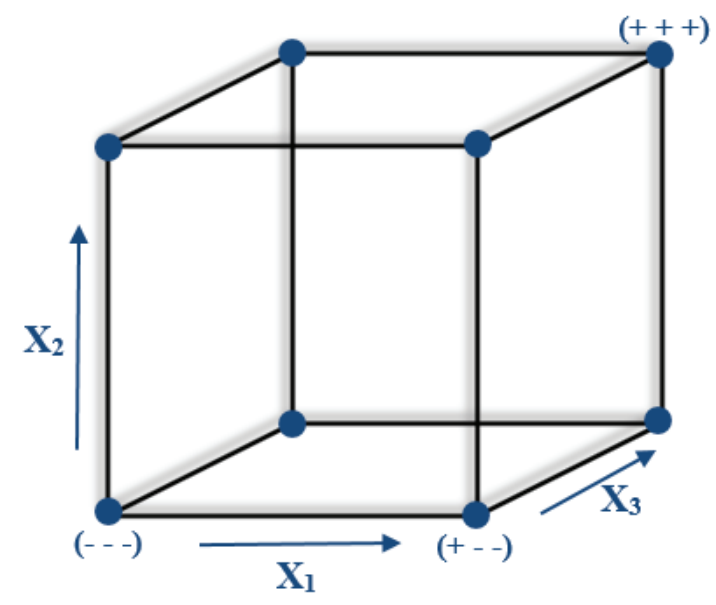

\begin{tabular}{|c|c|c|c|}
\hline Deneme No & Dağıtıc1 (\%) & $\begin{array}{c}\text { Sikıștırma } \\
\text { Basınc1 (Mpa) }\end{array}$ & $\begin{array}{c}\text { Bask1 Kuvveti } \\
(\mathrm{kN})\end{array}$ \\
\hline 1 & - & - & - \\
\hline 2 & - & - & + \\
\hline 3 & - & + & - \\
\hline 4 & - & + & + \\
\hline 5 & + & - & - \\
\hline 6 & + & - & + \\
\hline 7 & + & + & - \\
\hline 8 & + & + & + \\
\hline
\end{tabular}

Şekil 1. Tam faktöriyel tasarım (12). 
Örneğin 6 adet faktörün araştırılacağı bir çalışmada, tam faktöriyel tasarımda; $2^{6}=64$ deneme, Çözünürlük V kısmi faktöriyel tasarımda; $2^{5}=32$ deneme, Çözünürlük IV kısmi faktöriyel tasarımda; $2^{4}=16$ deneme ve Çözünürlük III kısmi faktöriyel tasarımda ise $2^{3}=8$ adet deneme yapılması gerekir (12).

\section{3. Üç seviyeli kısmi faktöriyel tasarım $\left(3^{\mathrm{k}-\mathrm{p}}\right)$}

Bu tasarım tipi, kısmi faktöriyel tasarımın 3 seviyeli halidir. L-tasarımları olarak da bilinir. Bazen nitel faktörlerin seviyesi 3 adet olabilir. Örneğin granülatör elek tipi faktörü için yuvarlak, kare ve rendeli şeklinde üç farklı seviye olabilir ya da üç farklı karıştırıcı tipinin karışım tekdüzeliğine etkisi değerlendiriliyor olabilir. Ayrıca nicel faktörlerin bağıml değişkenlere olabilecek etkisinin doğrusal olmadığından şüphelenildiği durumlarda kullanılması tavsiye edilebilir (11).

Örneğin akış düzeltici olarak kullanılan kolloidal silikon dioksitin düşük ve yüksek oranlarda kullanıldığında nispeten yüksek Carr İndeksi değerleri oluşturabileceği, ancak orta ( \%0.3) oranlarda kullanıldığında düşük Carr İndeksi değeri elde edilebileceğinden şüphelenilebilir.

\subsection{Plackett-Burman tasarımı}

Bu tasarım, iki seviyeli tam faktöriyelin çözünürlük III tasarımıdır. Sadece doğrusal modeller oluşturulabilir. Dolayısıyla ikili faktör etkileşimleri hakkında kestirimde bulunulamaz. Birçok faktör (örn. 9 ve üzeri) arasından, çıktılara yüksek etkisi olabilecek faktör sayısının az olabileceği (örn. 3-5 adet) öngörülebiliyorsa, elverişli bir yöntemdir. Bu tasarımda, faktör sayısı +1 adet kadar deneme yapılarak faktör sayısı düşürülebilinir $(10,12)$.

\subsection{Rechtschaffner tasarımı}

$\mathrm{Bu}$ tasarım, çözünürlük $\mathrm{V}$ tipindeki $2^{\mathrm{k}}$ ve $3^{\mathrm{k}}$ faktöriyel tasarımlarının doymuş parçalarından oluşan ortogonal tasarımlardır. Tüm ana faktör etkileri ve birinci dereceden ikili etkileşimler, birbirine karıştırılmadan kestirilebilir. Özellikle $2^{\mathrm{k}}$ Rechtschaffner tasarımı, 6 adet ve üzerinde faktör olduğunda ve ana faktör etkilerinin yanı sıra, bu faktörlerin birbirleriyle olan birinci derece etkileşimlerinin de değerlendirilmesi gereken durumlar için elverişlidir. $2^{\mathrm{k}}$ Rechtschaffner tasarımı için yapılması gereken deneme sayısı $\mathrm{N}=1+\mathrm{k}+\mathrm{k}(\mathrm{k}-1) / 2$ şeklindedir (11).

\subsection{D-Optimal tasarımı}

Bu tasarım hem eleme hem de formülasyon optimizasyonu amacıyla kullanılabilen, klasik tasarımların aksine bilgisayar türetimli bir tasarımdır. Bu tasarımda, bilgi matriksinin determinant değeri en yüksek hale getirilerek, öngörülen regresyon katsayılarının toplam varyansının en düşük değere gelmesi sağlanır $(10,13)$.

\section{7. İlaç formülasyonlarında istatiksel eleme kullanımı}

İstatiksel eleme yöntemi, literatür bilgisi, mevcut tecrübe ve risk değerlendirme gibi yaklaşımların kullanılması halinde bile, ürün kalitesini oluşturan çıktılara etkisi olabilecek muhtemel faktörlerin sayısı, hala çok fazla olduğunda kullanılması tercih edilen bir yöntemdir. Ana amaç, çıktılara en yüksek etkisi olan faktörlerin belirlenerek, toplam faktör sayısının düşürülmesidir. Ayrıca faktör seviyelerinin alt ve üst sınırlarında, çıktıların değişiminin nasıl olacağı hakkında çok az fikir sahibi olunan durumlar içinde uygulanması tercih edilebilir. Genel bir yaklaşım olarak, yapılan her türlü uğraşa rağmen hala 6 adet veya daha fazla faktör varsa, istatiksel eleme yöntemi kullanılmalıdır.

İlaç formülasyonlarında en çok tercih edilen istatiksel eleme yöntemleri, iki seviyeli kısmi ve tam faktöriyel tasarım ile Plackett-Burman tasarımı şeklindedir. Kontrollü salım bir formülasyonun, küçük ölçekli bir akışkan yatak granülatörde granüle edildiği bir çalışmada, $2^{3}+2$ (iki seviyeli üç faktör ve iki adet orta nokta) tam faktöriyel tasarımı uygulanmıştır. Polivinilpirolidon (PVP) miktarı, püskürtme hızı ve hidroksipropil metilselüloz (HPMC) viskozite farklılığının değerlendirildiği bu çalışmada, çözünme hızına sadece PVP miktarının istatiksel olarak anlamlı etkisinin olduğu tespit edilmiştir. Akışkan yatak granülatörde üretilen granül özellikleri üzerine proses koşullarının etkisinin araştırıldı̆̆ bir başka çalışmada, $2^{5-1}+2$ kısmi faktöriyel tasarımı kullanılmıștır. Etken madde partikül boyutu (ince ve kalın), bağlayıcı çözeltisi derişimi (\%11 ve \%16), püskürtme hızı (70 ve $110 \mathrm{~g} / \mathrm{dak}$ ) atomizasyon hava basinc1 (1 ve 3 bar) ve giriş havası yoğuşma sıcaklığı (5 ve $15{ }^{\circ} \mathrm{C}$ ) şeklinde faktörlerin bulunduğu bu çalışmada, sadece püskürtme hızı ve atomizasyon hava basıncının granül boyutuna yüksek oranda etkisinin olduğu tespit edilmiştir (14).

Plackett-Burman tasarımı, çok az sayıda deneme, yani faktör sayısından $(n)$ bir adet fazla $(n+1)$ deneme ile ana faktörlerin etkisini değerlendirebildiğinden, özellikle çok sayıda yardımcı madde ile etken maddenin geçimliliği ve belli bir işlev için olan birçok yardımcı maddeden hangisi 
ya da hangilerinin etkili olduğu vs. gibi çalışmalarda tercih edilmektedir. Durig ve Fassihi (15), yaptıkları bir çalışmada bu tasarımdan yararlanarak, piridoksal $\mathrm{HCl}$ etken maddesinin 11 adet yardımcı madde ile iki farklı sıcaklık ( 25 ve $55^{\circ} \mathrm{C}$ ) ve nem koşullarında (\%11 ve \%75 bağıl nem) geçimliliğini araştırmışlardır. Çalışmada manitol, laktoz ve mısır nişastasının piridoksal $\mathrm{HCl}$ ile kimyasal olarak geçimsiz olduğu, ancak çeşitli selüloz türevleri ile kolloidal silikon dioksitin güçlü bir stabilizasyon etkisinin olduğu tespit edilmiştir (15).

\section{YANIT YÜZEYİ MODELLEME (RSM) TASARIMLARI}

Yanıt yüzeyi yöntembilimi, proseslerin geliştirilmesi ve optimizasyonu için gerekli istatistiksel ve matematiksel tekniklerin birlikte kullanıldığı bir yaklaşımdır. Bağımlı değişkenler ile bunlara etki eden bağımsız değişkenler arasındaki ilişkiyi, en doğru şekilde belirlemek için kullanılan ampirik modelleme tekniklerini içerir. Oluşturulan bu model sayesinde; kritik kalite özelliklerinin istenen değerlerini sağlayan CPP ve CMA faktörlerinin seviye aralıkları tespit edilebilir $(16,17)$. Bir proses için tasarım alanı, bağımlı/ bağımsız her bir değişkenin kabul edilebilir aralıkta tanımlanmış olduğu $\mathrm{n}$ adet bağımsız değişken tarafından belirlenen $\mathrm{n}$ boyutlu bir alandır. Örneğin bir çalışmada iki proses değişkeni (bağımsız) ve ürüne ait bir kritik kalite özelliği (bağımlı) varsa, bağımsız değişken değerlerine karşı bağıml değişken değerlerinin oluşturduğu üç boyutlu grafikte, istenen kalite çıktısı değer aralığını sağlayan proses girdilerinin değer aralıkları, iki boyutlu bir yüzey oluşturur (yanıt yüzeyi) (17). Aksu ve arkadaşlarının (18) ondansetron içeren ağızda dağılan tablet (ODT) formülasyonunun optimizasyonu üzerine yaptıkları bir çalışmada, istenen ufalanabilirlik değerlerine karşı olması gereken dağıtıcı miktarı ve tablet baskı kuvvetini gösteren yanıt yüzeyi grafiği Şekil 2'de örnek olarak sunulmuştur.

RSM tasarımı, girdilere karşı yanıt değişkenlerinin olası değerlerini daha kesin ve doğru tahmin edebilmek için araştırmanın ilerleyen safhalarında, etkileşim, karesel (2. dereceden) ya da kübik (3. dereceden) modeller kurularak gerçekleştirilir. Bu aşamada, istatiksel olarak anlamlı şekilde çıktıları en fazla etkileyen CPP ve/veya CMA gibi kritik faktörler ve çalışılacak seviye aralıkları netleşmiş olmalıdır. Eleme tasarımlarının aksine burada amaç, faktörlerin yanıt değişkenlerini nasıl etkilediğinin daha derinlemesine anlaşılması, istenen yanıt değerlerini elde etmek için olması

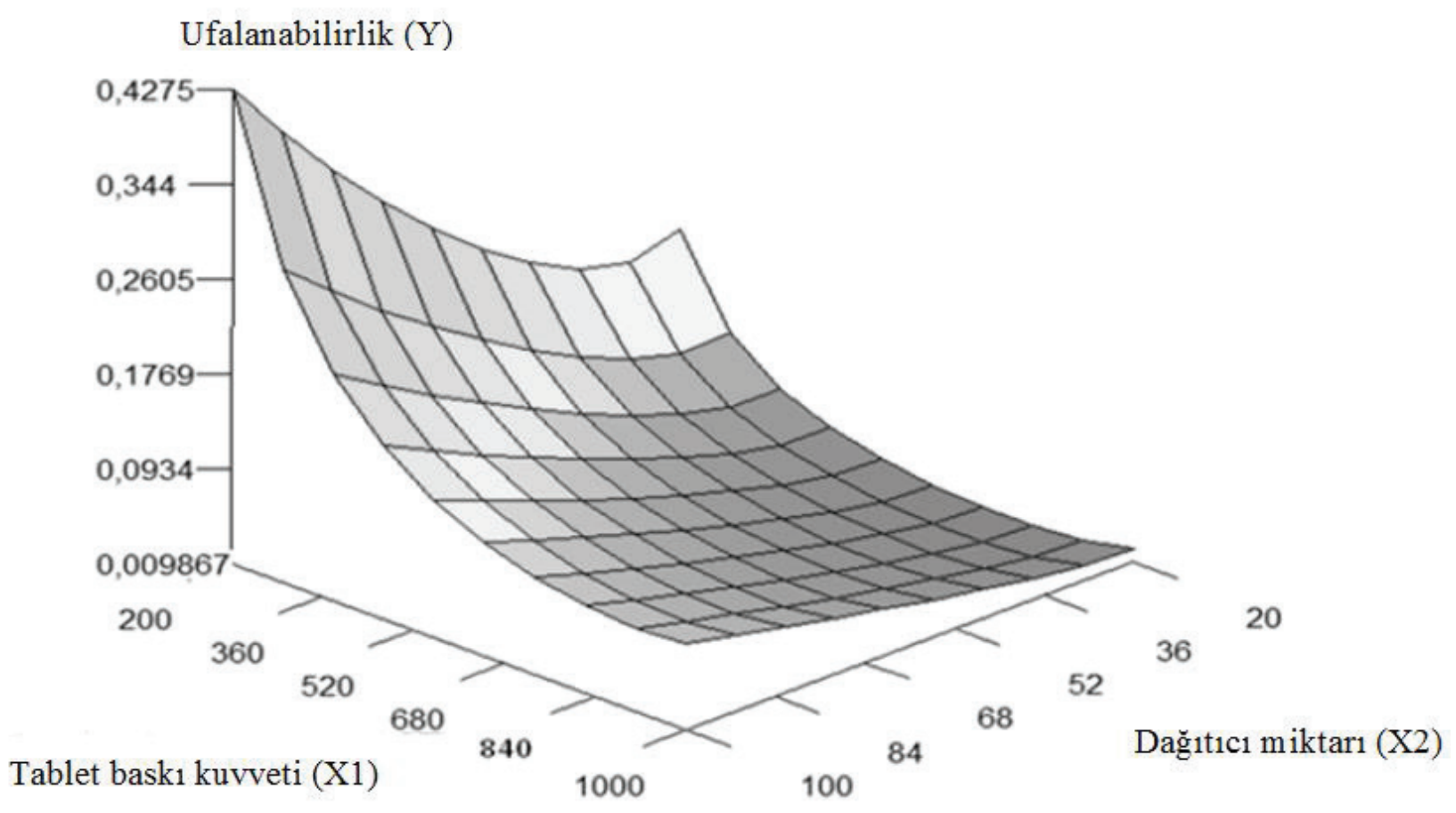

Şekil 2. İstenen ufalanabilirlik değerlerine karşı olması gereken dağıtıcı miktarı ve tablet baskı kuvvetini gösteren yanıt yüzeyi grafiği (18).*

*Tropical Journal of Pharmaceutical Research dergisinin yayıncısı olan Farmakoterapi Grubunun izni ile “Trop J Pharm Res 2014;13:137483" dergisinden alınmıștır. 
gereken faktör değerlerinin tahmin edilmesi ve bu şekilde ilgili ürünün prosesindeki en uygun çalışma aralığının (tasarım aralığı) belirlenmesi şeklindedir (11). Genellikle hem fazla deneme sayısı olmaması hem de istatiksel anlamlılığı yüksek olan, dolayısıyla daha güçlü tahmin özelliği olan modeller kurulabilmesi için 5 adetin üzerinde faktör kullanılmaması tercih edilmelidir.

$\mathrm{Bu}$ nedenle, formülasyonların optimizasyonu için kullanılacak olan RSM tasarımına geçmeden önce, istatiksel eleme tasarımı ile faktör sayısı düşürülmüş olmalıdır. $\mathrm{Bu}$ aşamada elde edilen deneysel veriler ve model analizine dayanılarak, RSM tasarımına aktarılacak olan faktörlerin seviyelerinde değişiklik yapılıp yapılmayacağına karar verilmelidir. Örneğin bir faktör eleme çalışması sonrasında, 7 faktörden sadece 3 tanesinin çıtıya olan etkisinin istatiksel olarak anlamlı $(\mathrm{p}<0.05)$ olduğu belirlenmiş olabilir. $\mathrm{Bu} 3$ faktörden 1 tanesinin regresyon katsayısı (çıktıyı etkileme kuvveti), diğer ikisine göre çok düşük kalıyor olabilir. $\mathrm{Bu}$ durumda deneme sonuçlarına da bakılarak, sebebin dar bir aralıkta seviye kullanılması olduğu düşünülüyorsa, RSM’ye geçmeden önce bu faktörün seviye aralı̆̆ 1 genişletilebilir. Ya da istatiksel eleme sırasında yapılan deneme sonuçlarına bakıldığında, örneğin RSM'ye aktarılacak olan istatiksel anlamlı bir faktörün düşük (-) veya yüksek (+) düzeyinde olduğu denemelerde, çıktı/lar istenen değerlerin çok fazla dışına çıkıyorsa, bu faktörün seviye aralı̆̆ı, RSM tasarımına geçmeden önce daraltılmalıdır. Optimizasyon amacıyla gerçekleştirilen DoE tipleri aşağıda sunulmuştur.

\subsection{Tam faktöriyel tasarım $\left(2^{\mathrm{k}}, 3^{\mathrm{k}}\right.$ veya karışık seviyeli)}

$\mathrm{Bu}$ tasarımlarda, yapılacak olan denemelerde faktör seviyelerinin tüm olası sıralanış biçimleri bulunur. k sayıda faktör için yapılacak olan deneme sayısı $2^{\mathrm{k}}$ veya $3^{\mathrm{k}}$ şeklinde olur. Alternatif olarak hem 2 hem de 3 ve üzerinde seviyeli faktörlerin olduğu karışık tam faktöriyel tasarım kullanılabilir. Nicel faktörlerin bağımlı değişkenlere olabilecek etkisinin doğrusal olmadığından şüphelenildiği durumlarda ve nitel bir faktörde 3 seviye olması gerektiği durumlarda $3^{\mathrm{k}}$ veya karışı tasarımın kullanılması önerilebilir. Faktör sayısı 4 ve üstünde olduğunda, $3^{\mathrm{k}}$ tasarımında deneme sayısı $\geq 81$ şeklinde çok fazla olacağ 1 için $2^{\mathrm{k}}$ tasarımı kullanılabilir, ancak mutlaka en az 2adet orta nokta ilave edilmelidir $(13,16)$.

\subsection{Merkezi birleşik tasarım (CCD)}

Bu tasarımlar tam karesel bir model oluşturabilirler. Özellikle faktör eleme aşamasında $2^{\mathrm{k}}$ veya $2^{\mathrm{k}-\mathrm{p}}$ faktöriyel tasarımları kullanılması halinde, faktöriyel tasarımda bulunmayan bazı denemelerin yapılması sayesinde ekonomik olarak tamamlanabilirler. Çünkü bu tasarımlar temelde, iki seviyeli faktöriyel tasarım (tam veya kısmi), yıldız noktaları (eksen noktaları) ve ilave merkez noktalarından oluşur. Daha önce yapılmış olan iki seviyeli bir tam/kısmi faktöriyel tasarımın yanıt yüzeyi grafiğinde düzlemsellikten ziyade dağ şeklini andıran eğimlilik görülmesi halinde (eğimliliğin görülebilmesi için tasarıma birkaç merkez noktası eklenmiş olmalıdır), bu eğimliliğin daha iyi tahmini için mevcut faktöriyel tasarıma yıldız noktaları ve ilave merkez noktaları eklenerek merkezi birleşik tasarıma dönüştürülebilir. Bu tasarımda bulunan eksen noktaları, faktör seviyelerinin alt ve üst limitlerinin dışında noktalar olabildiği için bu noktalarda yapılan denemelerin kabul edilemez çıktı değerleri oluşturabileceği göz önünde bulundurulmalıdır. Bu duruma, yıldız noktalarının tasarım merkezine uzaklığı olan a değeri değiştirilerek çözüm bulunabilir. Bu tasarımın çevresel sınırlı (CCC), ortogonal (CCO) ve yüzey merkezli (CCF) tipleri bulunmaktadır $(11,12)$.

Şekil 3’te, tam faktöriyel, kısmi faktöriyel ve birleşik tasarım noktaları gösterilmiştir. Her bir nokta, bir denemeyi temsil etmektedir. Şekillerin ortasındaki kar taneciği, deneysel hatanın araştırılması için yapılan tekrarlanmış merkez noktasını göstermektedir. Görüleceği üzere, istatiksel eleme amaçlı olarak da kullanılan tam faktöriyel tasarımda sadece köşe noktaları ve her zaman olmamakla birlikte merkez noktasında denemeler yapılmaktadır. Sadece eleme amaçlı olarak kullanılan ikinci satırdaki kısmi faktöriyel tasarımda ise, tam faktöriyelden daha az köşe noktası ve merkez noktası vardır. Ancak optimizasyon amacıyla kullanılan birleşik tasarımda ise, tam faktöriyeldeki tasarım noktalarına ek olarak, içi boş yuvarlaklarla gösterilen eksen noktaları da bulunmaktadır (11).

\subsection{Box Behnken tasarımı}

$\mathrm{Bu}$ tasarım, CCD tasarımının aksine içinde tam veya kısmi faktöriyel tasarım içermeyen üç seviyeli tasarımlardır. Tüm tasarım noktaları, bir küpün veya hiperkübün kenarlarının ortasında bulunur ve bu noktaların hepsi bir kürenin yüzeyine yerleştirilmiştir. Bu tasarımlarda 1. ve 2. dereceden model katsayılarının etkili bir şekilde kestirimi sağlanabilir. Ancak bu tasarımın kullanılabilmesi için en azından üç faktörün nicel olması gerekir. Aynı sayıda faktörün olduğu durumlarda, CCD tasarımına göre daha az nokta içerdiği için daha ekonomiktir. Fakat içinde faktöriyel tasarım bulundurmadığı için ardışık sıralı denemeler için uygun olmadığı, yani yapılmış bir faktöriyel tasarımdaki denemelerle birleştirilemeyeceği göz önünde bulundurulmalıdır. $\mathrm{Bu}$ tasarımda CCD tasarımında olduğu gibi eksen noktaları bulunmadığı için faktör seviyelerinin alt ve üst limitlerinin 


\begin{tabular}{|c|c|c|c|}
\hline Tasarım tipi & 2 adet faktör & 3 adet faktör & $\begin{array}{c}\text { 3'ten fazla faktör } \\
(>3)\end{array}$ \\
\hline $\begin{array}{l}\text { Tam faktöriyel } \\
\text { tasarım }\end{array}$ & $\approx$ & & Hiperküp \\
\hline $\begin{array}{c}\text { K1smi } \\
\text { faktöriyel } \\
\text { tasarım }\end{array}$ & & & $\begin{array}{l}\text { Hiperkübün dengeli } \\
\text { bir bölümü }\end{array}$ \\
\hline $\begin{array}{c}\text { Merkezi } \\
\text { birleşik } \\
\text { tasarım }\end{array}$ & & & $\begin{array}{l}\text { Hiperküp }+ \text { eksen } \\
\text { noktaları }\end{array}$ \\
\hline
\end{tabular}

Şekil 3. Tam faktöriyel, kısmi faktöriyel ve birleşik tasarım noktalarının resmedilmesi (11).

dışına çıkılmaz. Ayrıca bu tasarımda, tüm faktörlerin aynı anda düşük (-) ve aynı anda yüksek (+) olduğu denemeler bulunmaz. Üç faktörlü Box Behnken tasarımında 15 adet ve dört faktörlü tasarımda ise 27 adet deneme yapılması gerekir $(11,16)$.

\subsection{Doehlert tasarımı}

Doehlert tasarımı, başka faktör aralıklarına geçebilme ve genişletilebilme gibi özelliklere sahip olan karesel modeller oluşturan bir tasarımdır. Tüm ana faktör etkileri, birinci dereceden etkileşimler ve karesel etkiler birbirine karıştırılmadan tahmin edilebilir. CCD tasarımlarıyla benzer özelliklere sahiptir. Geometrik olarak, hiper-üçgenler (simpleks) içeren iç içe geçmiş çokyüzlü şekillerdir. Faktör sayısının $\mathrm{k}$ olduğu ve merkez noktası içermeyen durumda deneme sayısı $\mathrm{N}=1+\mathrm{k}+\mathrm{k}^{2}$ şeklindedir. Bu tasarımlara mutlaka 3-4 adet merkez noktası eklenmesi tavsiye edilmektedir $(10,11)$.

\subsection{D-Optimal tasarım}

Bu tasarımda faktör seviyelerinin oluşturduğu deneysel bölge, düzenli hiper-üçgen şeklinde değildir, düzensiz çokyüzlü şeklindedir. Klasik tasarımların uygulanmasının mümkün olmadığı, faktör seviyelerinde çeşitli kısttlamalar olduğu, dolayısıyla düzensiz şekilli deneysel bölgenin oluştuğu, nitel faktörlerin fazla olduğu ve ikiden fazla seviyelerinin olduğu, hem proses hem de formülasyon bileşeni faktörlerinin birlikte olduğu durumlarda tercih edilebilir (11). 


\subsection{Karışım tasarımı}

Bu tasarım, optimizasyonu yapılacak olan üründeki çıktılara etki eden ana faktörlerin formülasyon içeriğinde farklı amaçlar için kullanılan maddeler olduğu, RSM tasarımlarının özel bir türüdür. Karesel ve kübik modeller oluşturulabilir. $\mathrm{Bu}$ tasarımda yanıt değişkenleri, formülasyon karışımı içindeki farklı maddelerin oranlarının bir fonksiyonudur. Formülasyon (karışım) faktörlerinin seviyeleri, toplam miktarın oranı olarak ifade edilir ve $0-1$ arasında değişen değerler alabilirler. Dolayısıyla her denemede formülasyon faktörlerinin toplamı sabittir ve eğer sabit tutulan (örn. etken madde) bir madde yoksa 1'e eşittir. Bu tasarımlarda aynı zamanda hem proses faktörleri hem de eğer karışımın toplam miktarı da çıktılara etki ediyorsa, toplam miktar faktörü de kullanılabilir. Tasarımı oluşturma sırasında faktörler tanımlanırken, karışım faktörlerinden birisi, toplam miktara tamamlayıcı görevi olan dolgu maddesi olarak tanımlanabilir. $\mathrm{Bu}$ şekilde her bir denemedeki karışımın oranını, eğer sabit tutulan bir madde yoksa 1'e tamamlayacak olan dolgu maddesinin, çıktılar üzerinde etkisinin önemli olmadığı ya da göz ardı edilebilir olduğu varsayılır. Hiperüçgen ağırlık merkezi (centroid), hiper-üçgen kafes (lattice) ve uç köşe noktaları (extreme vertices) şeklinde tasarım türleri bulunmaktadır. Ana amacın, ağırlıklı olarak formülasyondaki maddelerin en uygun kullanım oranlarının bulunması olduğu durumlara uygun bir tasarımdır (11).

Şekil 4’te, bağlayıcı, dağıtıcı ve kaydırıcı madde miktarları şeklinde üç adet kritik faktörün olduğu iki farklı karışım tasarımı gösterilmiştir. Soldaki tasarım oldukça sade ve basittir. Üç adet köşe noktası (bileşenlerin \%100 saf halleri), üç adet kenarların merkez noktası (iki bileşenli karışımlar) ve üç bileşenin karışımından oluşan bir adet ağırlık merkezi noktası vardır. Sağdaki tasarımda ise, düzenli üçgen kafes deseninde çok sayıda nokta içermektedir. Bu şekilde karışım tasarımı sınırları içinde her bir bileşenin beş seviyesinin tüm olası sıralanış biçimleri bulunmaktadır. Bu haliyle beş seviyeli tam faktöriyel tasarıma benzemektedir. Ancak beş seviyeli tam faktöriyel tasarımda bulunan " $\% 25, \% 25, \% 25$ " veya “\%50,\%75,\%100” gibi bazı sıralanış biçimleri bulunmaz. Çünkü bu sıralanış biçimleri, karışım tasarımı hiperüçgeninin içinde değildir (12).

\subsection{Rechtschaffner tasarımı}

$\mathrm{Bu}$ tasarımların optimizasyon amaciyla kullanımlarında, mutlaka en azından 3-4 adet orta nokta eklenmesi tavsiye edilmektedir (11).

\section{8. İlaç Formülasyonlarında RSM Tasarımlarının Kullanımı}

RSM tasarımlarında amaç; ana faktör etkilerinin yanı sıra faktör etkileşimleri (iki ya da daha fazla faktörün sinerjik etkisi), karesel etkiler ve hatta bazı tasarımlarda kübik terimlerin kestirimi sayesinde faktörler ile yanıt değişkenleri arasındaki ilişkinin derinlemesine anlaşılmasıdır. Bu sayede faktörlerin optimum değer aralıklarının bulunması, proses sorunlarının çözülmesi ve proses değişkenliklerine karşı daha az hassas olan sağlam proseslerin geliştirilebilmesi sağlanabilmektedir. $\mathrm{Bu}$ amaçla gerçekleştirilen bazı çalışmalardaki faktörler, faktör seviyeleri, kullanılan DoE tipi, yapılan deneme sayısı ve kullanılan bilgisayar programları Tablo 1'de örnek olarak gösterilmiştir.

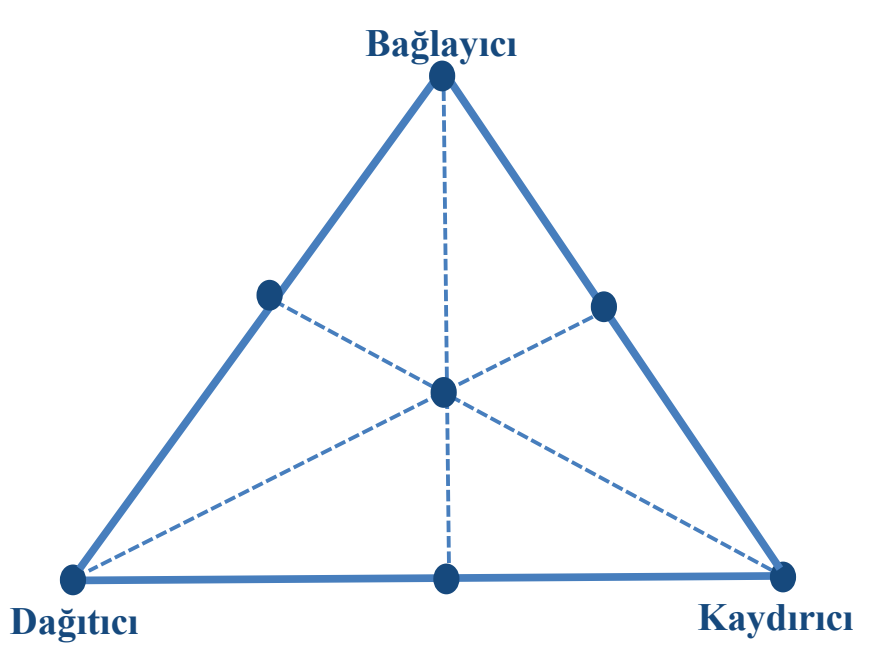

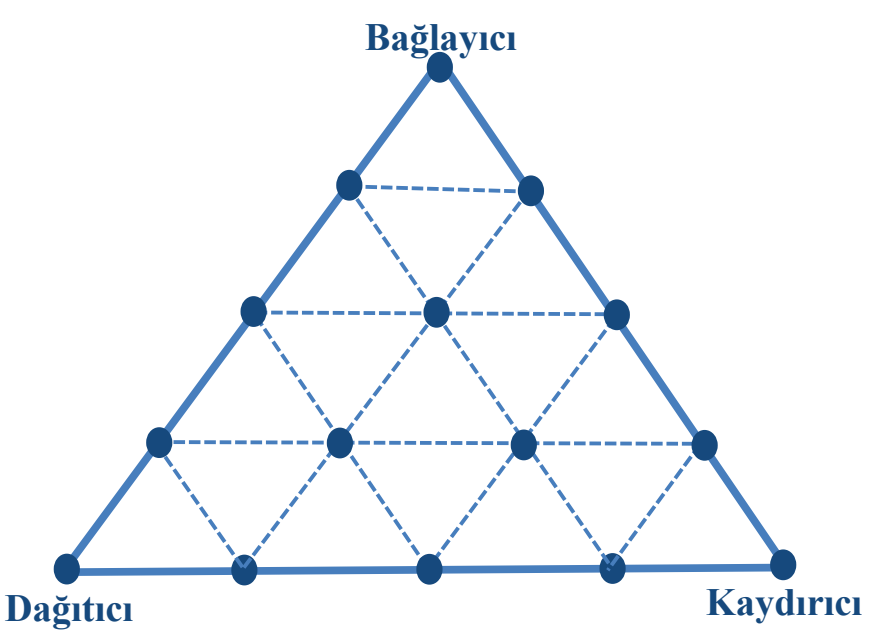

Şekil 4. Üç faktörlü karışım tasarımları (12). 
Tablo 1'in ilk satırında verilen çalışmada (19), üç faktörden iki tanesi nitel, bir tanesi niceldir. İki tanesi üç seviyeli, bir tanesi iki seviyelidir. Nitel faktörlerin çoğunlukta olduğu ve tek bir nicel faktörün bulunduğu bu çalışmada, merkez noktası içermeyen köşe noktalarının tümünden oluşan bir tam faktöriyel tasarım seçilmiştir. Nitel faktörlerin, nicel faktörler gibi ortası, biraz fazlası ya da azı gibi bir özelliği yoktur. Örneğin optimizasyon sonucunda kaydırıcı miktarı için \%1.5 ila \%3.5 aralığında sayısal bir değer belirlenebilir. Ancak kaydırıcı tipi için sadece tek bir kaydırıcı, en uygun kaydırıcı olarak belirlenebilir (bahsi geçen çalışmada kaydırıcıların birlikte karışım hali değerlendirilmemiştir). Bu durumda eksen noktaları içeren birleşik tasarımlar veya orta/ara noktalar içeren Box Behnken ve Doehlert gibi tasarımlar uygun olmayacaktır.
Benzer şekilde değerlendirildiğinde, üçüncü satırda verilen çalışmada $2^{4}$ tam faktöriyel tasarımı kullanılarak 16 deneme yapılmıştır (21). Ancak tablet sertliği ve tablet ağırlı̆̆ değişiminin kalite çıktısı olarak ölçüldüğü bu çalışmada, tüm faktörler sayısal ve ayarlanabilirdir. Dolayısıyla, optimizasyon amacıyla gerçekleştirilen bu tasarıma en azından 2 adet orta nokta eklenmiş, yani sadece 16 yerine 18 deneme yapılmış olsaydı, daha iyi tahmin yeteneğine sahip bir model elde edilebilirdi. Öte yandan, doğrusal olmayan bir davranışın yüksek ihtimalle beklenmediği böyle bir çalışmada, çok fazla deneme yapmayı gerektiren üç seviyeli $3^{4}$ tam faktöriyel tasarımın kullanılmaması da doğru bir seçimdir.

Tablo 1. Bazı çalışmalarda kullanılan DoE tipi, faktörler, faktör seviyeleri, deneme sayısı ve kullanılan bilgisayar programları.

\begin{tabular}{|c|c|c|c|c|}
\hline Faktörler & Seviyeler & DoE Tipi / Deneme sayısı & $\begin{array}{l}\text { Bilgisayar } \\
\text { Programı }\end{array}$ & Referans No \\
\hline $\begin{array}{l}\text { Kaydırıcı tipi } \\
\text { Kaydırıcı miktarı } \\
\text { Briket baskı }\end{array}$ & $\begin{array}{c}\text { Gliseril dibehenat, Gliserol distearat ve } \\
\text { Sodyum stearil fumarat } \\
\% 1.5, \% 2.5 \text { ve } \% 3.5 \\
\text { Yok ve Var }\end{array}$ & $\begin{array}{l}\text { Karışık seviyeli tam } \\
\text { faktöriyel tasarım / } 18 \\
\text { deneme }\end{array}$ & $\begin{array}{l}\text { Minitab } 17.1 \text { ve } \\
\text { INForm V5.1 }\end{array}$ & 19 \\
\hline $\begin{array}{l}\text { Polimer tipi } \\
\text { Polimer konsantrasyonu } \\
\text { Özgül ağırlık }\end{array}$ & $\begin{array}{c}\text { HPMC ve Khaya zamk } 1 \\
\% 5 \text { ve } \% 15 \\
0.80 \text { ve } 0.90\end{array}$ & $\begin{array}{c}2^{3} \text { tam faktöriyel tasarım / } \\
8 \text { deneme }\end{array}$ & Minitab 14.2 & 20 \\
\hline $\begin{array}{c}\text { Tablet baskı hızı (tablet/saat) } \\
\text { Baskı makinesi dozajlama sistemi konumu } \\
\text { Alt ve üst zımba arasındaki minimum mesafe } \\
\text { Üst zımba kafası ve sıkıştırma silindiri arasındaki } \\
\text { mesafe }\end{array}$ & $\begin{array}{l}100000 \text { ve } 400000 \\
4.0 \mathrm{~mm} \text { ve } 6.0 \mathrm{~mm} \\
0.7 \mathrm{~mm} \text { ve } 2.0 \mathrm{~mm} \\
2.2 \mathrm{~mm} \text { ve } 3.0 \mathrm{~mm}\end{array}$ & $\begin{array}{c}2^{4} \text { tam faktöriyel tasarım / } \\
16 \text { deneme }\end{array}$ & $\begin{array}{c}\text { Minitab versiyon } \\
7\end{array}$ & 21 \\
\hline $\begin{array}{c}\text { İç faz hacmi } \\
\text { Yüzey aktif madde derişimi }(\mathrm{a} / \mathrm{h}) \\
\text { Karıștırma hızı }\end{array}$ & $\begin{array}{c}5 \mathrm{ml}, 7.5 \mathrm{ml} \text { ve } 10 \mathrm{ml} \\
\% 0.05, \% 0.075 \text { ve } \% 0.1 \\
1000,1500 \text { ve } 2000 \mathrm{rpm} \\
\end{array}$ & $\begin{array}{c}2^{3} \text { faktöriyel tasarım / } 11 \\
\text { deneme }\end{array}$ & $\begin{array}{l}\text { Design-Expert } \\
\text { Software }\end{array}$ & 22 \\
\hline $\begin{array}{c}\text { HPMC miktarı } \\
\text { Laktoz miktarı } \\
\text { Mikrokristalin selüloz miktarı } \\
\text { Kolloidal silikon dioksit miktarı }\end{array}$ & $\begin{array}{l}50-215 \mathrm{mg} \\
0-100 \mathrm{mg} \\
25-75 \mathrm{mg} \\
10-60 \mathrm{mg}\end{array}$ & $\begin{array}{l}\text { Karışım tasarımı / } 21 \\
\text { deneme }\end{array}$ & Minitab 16 & 23 \\
\hline $\begin{array}{c}\text { HPMC dereceleri } \\
650 \text { mg tablette toplam HPMC miktarı } \\
\text { Her bir HPMC derecesinin karışım içindeki } \\
\text { miktar aralığı }\end{array}$ & $\begin{array}{c}\text { K100, K4M ve K15M } \\
143.00 \mathrm{mg} \\
23.83 \mathrm{mg}-143.00 \mathrm{mg}\end{array}$ & $\begin{array}{l}\text { Karışım tasarımı - hiper- } \\
\text { üçgen kafes (lattice) / } 10 \\
\text { deneme }\end{array}$ & Minitab 16 & 24 \\
\hline $\begin{array}{c}\text { Okara miktarı } \\
\text { Guar zamkı miktarı } \\
\text { Maltodekstrin miktarı } \\
\text { Avicel PH-101 miktarı }\end{array}$ & $\begin{array}{c}\% 25-\% 50 \\
\% 0-\% 20 \\
\% 5-\% 15 \\
\% 18-\% 68\end{array}$ & $\begin{array}{l}\text { D-Optimal karışım } \\
\text { tasarımı / } 20 \text { deneme }\end{array}$ & $\begin{array}{c}\text { Design-Expert } \\
7.0\end{array}$ & 25 \\
\hline $\begin{array}{l}\text { Sodyum nişasta glikolat miktarı } \\
\text { Kroskarmeloz sodyum miktarı }\end{array}$ & $\begin{array}{l}\% 5.0-\% 8.0 \\
\% 2.0-\% 5.0\end{array}$ & $\begin{array}{l}\text { Merkezi birleşik tasarım } \\
\text { (CCD) / } 13 \text { deneme }\end{array}$ & Minitab 16 & 26 \\
\hline $\begin{array}{c}\text { Sicaklik } \\
\text { Su aktivitesi } \\
\text { pH }\end{array}$ & $\begin{array}{c}11^{\circ} \mathrm{C}-31^{\circ} \mathrm{C} \\
0.86-0.98 \\
3.5-6.5\end{array}$ & $\begin{array}{l}\text { Doehlert tasarımı / } 13 \\
\text { deneme }\end{array}$ & $\begin{array}{l}\text { Nemrod software } \\
\quad \text { (LPRAI) }\end{array}$ & 27 \\
\hline $\begin{array}{l}\text { Polimer/İlaç oranı } \\
\text { Yüzey aktif madde derişimi } \\
\text { Sonikasyon süresi }\end{array}$ & $\begin{array}{c}50,75 \text { ve } 100 \\
\% 3, \% 4 \text { ve } \% 5 \\
30,45 \text { ve } 60 \text { dakika }\end{array}$ & $\begin{array}{c}\text { Box Behnken tasarımı / } 15 \\
\text { deneme }\end{array}$ & $\begin{array}{l}\text { Quantum XL } \\
\text { (Sigma) }\end{array}$ & 28 \\
\hline $\begin{array}{c}\text { HPMC miktarı } \\
\text { Aerosil miktarı } \\
\text { Magnezyum stearat miktarı }\end{array}$ & $\begin{array}{c}\% 1, \% 3 \text { ve } \% 5 \\
\% 0.3, \% 0.6 \text { ve } \% 0.9 \\
\% 0.5, \% 1.5 \text { ve } \% 2.5\end{array}$ & $\begin{array}{c}\text { Box Behnken tasarımı / } 15 \\
\text { deneme }\end{array}$ & $\begin{array}{c}\text { Statgraphics } \\
\text { Plus versiyon } 4 \\
\text { (Manugistics Inc) }\end{array}$ & 29 \\
\hline
\end{tabular}




\section{DoE SEÇIMM REHBERI}

Seçilen tasarım ne olursa olsun, denemelerin standart sıralamada yapılması yerine, rastgele sıralamada gerçekleştirilmesi çok yararlıdır. Böylelikle tasarıma dahil edilmemiş olan ve yanıt değişkenlerine etkisinin olmadığ 1 varsayılan dış faktörlere karşı koruma sağlanmış olur. Ayrıca hem ekstra deneme yapilmasina sebep olmayıp, hem de daha fazla bilgi sunduğu için mümkün olan her durumda dizileme (bloklama) yapılmalıdır. Örneğin 16 denemeden oluşan $2^{4}$ tam faktöriyel tasarımını yapacağımız sırada elimizdeki etken madde serilerinden birisinin sadece 8 denemeye yeteceğini varsayalım. Bu durumda toplam deneme sayısı değişmeden 8'er deneme iki farklı API serisiyle olacak şekilde 2 dizi (blok) kullanılabilir. Bu şekilde modelleme sonuçlarında, iki farklı API serisi, yani iki dizi arasında çıttılara etki eden kalite farkı olup olmadığı tespit edilebilir $(11,13)$.

Yapılacak olan çalışmanın amacı, faktör sayısı ve tipine göre hazırlanmış olan DoE seçim rehberi Şekil 5'de sunulmuştur. Ancak bu rehberin sadece temel düzeyde tavsiye niteliğinde olduğu, burada belirtilmeyen farklı yaklaşımların ve farklı tasarım tiplerinin de mevcut olduğu göz önünde bulundurulmalıdır.

\section{ALTERNATIIF YAKLAŞIMLAR}

Şunu da belirtmek gerekir ki, ilaç formülasyonu geliştirme aşamasında kritik faktörler ile kritik yanıt değişkenleri arasındaki ilişkiyi model oluşturarak derinlemesine anlamak ve optimizasyon yapabilmek için uygulanabilecek tek yöntem, DoE değildir. Bu amaçla uygulanabilen ve üstelik DoE'de olduğu gibi belli bir tasarıma sadık kalarak denemelerin yapılmak zorunda olmadığı, yapay sinir ă̆ (ANN), gen ekspresyon programlama (GEP) ve nörobulanık mantık (NFL) modellemelerini içeren bilgisayar programları kullanılarak yapılan birçok başarılı çalışma da bulunmaktadır $(18,30-35)$.

ANN, insan beyninin bazı nörolojik işlem yeteneklerini taklit etme üzerine odaklanan bilgisayar teknikleridir. Sunulan bilgide karışık ve gizli (latent) örnekleri algılama ve ayırt etme yeteneğine sahiptirler. ANN'lerin bu özellikleri, sunulan verilerden gizli bilgiyi çekip alabilmeleri, modelleme ve tahmin amaçları için kullanımında çok güçlü araçlar olduklarını kanıtlamaktadır. GEP ya da diğer adıyla genetik algoritma, farklı şekil ve büyüklükteki karmaşık sinir ağlarını (fenotip) haritalandıran sabit uzunluktaki doğrusal kromozomları (genotip) kullanarak bütünsel ağ

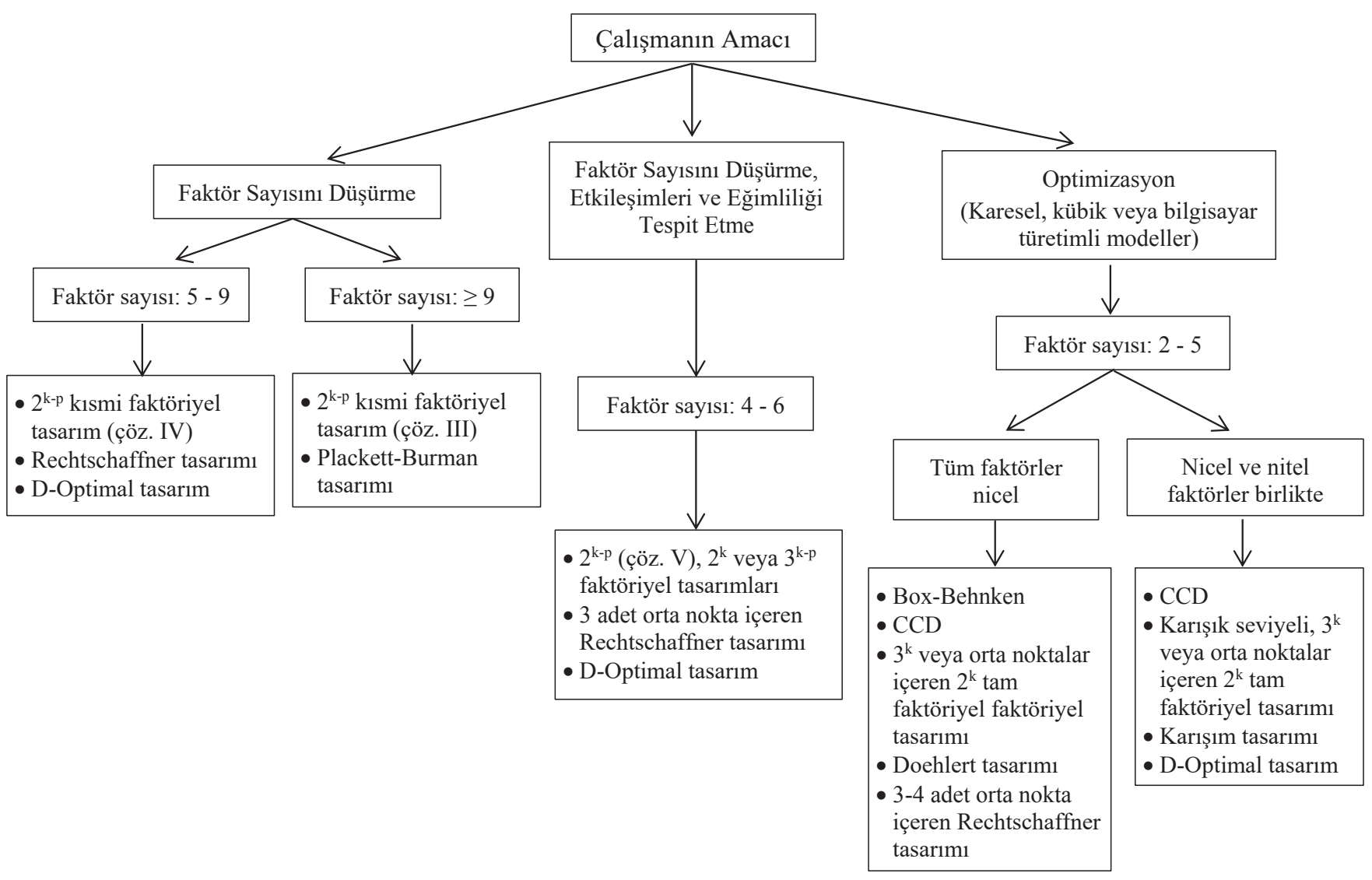

Şekil 5: DoE seçim rehberi (özgün şekil). 
tetiklemesi başlatan bir işlem süreci (algoritma) olarak ifade edilir. ANN’nin en büyük özelliği, aralarında doğrusal ilişki bulunmayan veri setleri için umut vaat eden bir modelleme tekniği olmasıdır. GEP ise, karmaşık ve çok boyutlu araştırma alanlarında en güçlünün ayakta kalması (doğal seleksiyon) ilkesine dayanarak en uygun bütünsel çözümler üreten bir işlemler sürecidir (36).

Ayrıca formülasyon geliştirmede sağlam bir optimizasyon yapmayı garanti etmek için hem DoE uygulayarak RSM modeli oluşturmak hem de aynı deneme verilerini kullanarak ANN, GEP veya NFL modelleri de oluşturulabilir. Demir ve arkadaşları (19), deksketoprofen trometamol tablet formülasyonunun optimizasyonu için önce Minitab programında karışık seviyeli tam faktöriyel tasarımını uygulayarak etkileşim modeli oluşturmuş, sonrasında aynı deneme verilerini hem ANN hem de GEP modellemesini içeren INForm programında modelleme yapmak için kullanmışlardır. Bu şekilde aynı deneme verileri, farklı bilgisayar programlarıla değerlendirilerek, en iyi korelasyonu

The Use and Selection of Design of Experiments (DoE) in the Development of Drug Product Formulation

\section{ABSTRACT}

In recent years, despite of the increasing use of design of experiments (DoE) in the development of drug product formulation, it has still not been sufficient. It has been known that using DoE is very useful particularly formulation of solid and semi-solid dosage forms including many components and many process parameters with unknown effect on outputs. Proper use and selection of the DoE is also important at least as using DoE in the development of drug product formulation instead of the old approaches such as trial and error. Non-correctly selected type of DoE or inappropriately applied experiments and measurements results not only wasted resources and time, but yapan modelleme seçilebilmektedir. Optimizasyon amacıyla Minitab, ANN ve GEP (INForm) üçlüsünü kullanmanın yanı sıra (36), başka modelleme programlarıla da optimizasyon modelleri oluşturulması desteklenmelidir.

\section{SONUÇ}

İlaç sektöründe ürün geliştirme amacıyla yapılan fazladan her bir deneme ve numune analizinin, çok fazla para, zaman ve işgücü kaybı demek olduğu günümüzde, amaca ve doğru bir şekilde sonuca ulaşmaya hizmet eden uygun DoE tipinin seçilmesi, uygulanması ve yorumlanması çok önemli olmaktadır. Uygun deney tasarımlarının seçilmesi sayesinde; yapılacak olan geliştirme çalışmasındaki kritik faktörler ve uygun seviyeleri, az sayıda deneme ile belirlenebilir. Ayrıca proses ve formülasyonun optimizasyonu amacıla, bu kritik faktörler ile kritik kalite özellikleri arasındaki ilişkiyi en iyi açıklayan ve doğru kestirimlerde bulunabilen matematiksel modeller oluşturulabilir. also often produces confusing or misleading data. In this review, summary information about DoE, selection of suitable type of DoE, reduction of the number of factors by using statistical screening and optimization of the drug formulations using response surface modeling (RSM) are intended to give, also briefly mentioned about the application of these methods in the development of pharmaceutical formulation. A lot of quality information (mathematical models) can be produced from the few trials conducted by means of selecting and implementation of the correct type of DoE. Thus, the development time and cost can be reduced significantly. Developed product may also have a robust process which is not sensitive to variations.

Key Words: Design of experiments, formulation development, drug, response surface modeling, optimization.

\section{KAYNAKLAR}

1. Haaland PD. Experimental Design in Biotechnology ( $\left.1^{\text {st }} e d\right)$. Marcel Dekker Inc, New York. 1989. pp.3-92.

2. Bass I. Six Sigma Statistics with EXCEL and MINITAB ( $\left(1^{\text {st } e d) . ~}\right.$ McGraw-Hill Professional, USA. 2007, pp.275-288.

3. Box GEP, Hunter WG, Hunter JS. Statistics for Experimenters. John Wiley \& Sons Inc, New York. 1978, pp.298-487.

4. Mason RL, Gunst RF, Hess JL. Statistical Design and Analysis of Experiments: With Applications to Engineering and Science ( $2^{\text {nd }}$ ed). John Wiley \& Sons Inc, Hoboken. 2003, pp.109-139.

5. Antony J. Design of Experiments for Engineers and Scientists ( $2^{\text {nd }}$ ed). Elsevier Inc. 2014, pp.7-125.
6. Hwang RC, Kowalski DL. Design of experiments for formulation development. Pharm Technol 2005. Available at; http://www.pharmtech.com/search/apachesolr_search/.\%20 Design\%20of\%20experiments\%20for\%20formulation\%20 development [Son erişim tarihi: 01.11.2016].

7. Shivhare M, McCreath G. Practical considerations for DoE implementation in quality by design. Bioprocess Int 2010; 8: 22-30.

8. Qiu Y, Zhang G. Development of modified-release solid oral dosage forms. In: Developing solid oral dosage forms: Pharmaceutical theory and practice. Editors: Qui Y, Chen Y, Zhang GGZ. Academic Press, Burlington. 2009, pp.501-517. 
9. Lionberger RA, Lee SL, Lee L, Raw A, Yu LX. Quality by design: Concepts for ANDAs. AAPS J 2008; 10: 268-76.

10. Kumar BP, Karimulla SK. Solid lipid nanoparticles - a brief review. Int J Adv Pharm 2012; 2: 35-55.

11. Eriksson L, Johansson E, Kettaneh-Wold N, Wikström C, Wold S. Design of experiments: Principles and applications ( $3^{\text {rd }}$ ed). MKS Umetrics AB, Sweden. 2008, pp.7-386.

12. Esbensen KH, Guyot D, Westad F, Houmoller LP. Multivariate data analysis in practice: An introduction to multivariate data analysis and experimental design $\left(5^{\text {th }} \mathrm{ed}\right)$. Aalborg University, Denmark. 2002, pp.361-479.

13. Montgomery DC. Design and analysis of experiments $\left(5^{\text {th }} e d\right)$. John Wiley\&Sons Inc, New York. 2000, pp.170-511.

14. Yamamoto K, Shao ZJ. Process Development, Optimization, and scale-up: Fluid-bed granulation. In: Developing solid oral dosage forms: Pharmaceutical theory and practice ( $1^{\text {sted}}$ ). Editors: Qui Y, Chen Y, Zhang GGZ. Academic Press, Burlington. 2009, pp.708-712.

15. Dürig T, Fassihi AR. Identification of stabilizing and destabilizing effects of excipient-drug interactions in solid dosage form design. Int J Pharm 1993; 97: 161-70.

16. Myers RH, Montgomery DC, Anderson-Cook CM. Response surface methodology: Process and product optimization using designed experiments ( $4^{\text {th }}$ ed). John Wiley and Sons Inc, Hoboken NJ. 2016, pp.1-12, 81-543.

17. Porter WR. Applied statistics in product development. In: Developing solid oral dosage forms: Pharmaceutical theory \& practice. Editors: Qiu Y, Chen Y, Zhang GGZ, Liu L, Porter WR. Academic Press, Burlington USA. 2009, pp. 255-259.

18. Aksu B, Yegen G, Purisa S, Cevher E, Ozsoy Y. Optimisation of ondansetron orally disintegrating tablets using artificial neural networks. Trop J Pharm Res 2014; 13: 1374-83.

19. Demir Ö, Aksu B, Özsoy Y, Araman A. Optimization of dexketoprofen trometamol tablet formulations utilizing different modeling techniques and the quality by design. Lat Am J Pharm 2016; 35: 813-25.

20. Odeniyi MA, Jaiyeoba KT. Optimization of ascorbic acid tablet formulations containing hydrophilic polymers. Farmacia 2009; 57: 157-66.

21. Ferreira GN, Silva MGR, Fraga AGM, Pereira da Silva LCR, Lira LM, Rodrigues CR, Castro HC, PEREİRA DE Sousa V, Cabral LM. Preparation and scale up of extended-release tablets of bromopride. Braz J Pharm Sci 2014; 50: 291-300.

22. Munot NM, Bajaj AN. Formulation and evaluation of gastroretentive indapamide micro balloons in combination with telmisartan minitablets. Int J Pharm Bio Sci 2011; 2: 14152.

23. Monajjemzadeh F, Hamishehkar H, Zakeri-Milani P, Farjami A, Valizadeh H. Design and optimization of sustained-release divalproex sodium tablets with response surface methodology. AAPS PharmSciTech 2013; 14: 245-53.
24. Uğurlu T, Karaçiçek U, Rayaman E. Optimization and evaluation of clarithromycin floating tablets using experimental mixture design. Acta Pol Pharm 2014; 71: 31121.

25. Zen NIM, Gani SSA, Shamsudin R, Masoumi HRF. The use of D-Optimal mixture design in optimizing development of okara tablet formulation as a dietary supplement. Sci World J 2015; 2015: 1-7.

26. Shakya S. Formulation and optimization of immediate release tablet of sitagliptin phosphate using response surface methodology. Int J Pharm Biol Med Sci 2015; 4: 7-12.

27. Sautour M, Rouget A, Dantigny P, Divies C, Bensoussan M. Application of Doehlert design to determine the combined effects of temperature, water activity and $\mathrm{pH}$ on conidial germination of Penicillium chrysogenum. J Appl Microbiol 2001; 91: 900-6.

28. Matlhola K, Katata-Seru L, Tshweu L, Bahadur I, Makgatho G, Balogun M. Formulation and optimization of Eudragit RS PO-Tenofovir nanocarriers using box-behnken experimental design. J Nanomater 2015; 2015: 1-11

29. El-Say KM, Refaey TA, Samy AM, Badawi AA. Box-Behnken design for optimization of formulation variables to improve the flowability and compressibility of bezafibrate. J Pharm Sci 2011; 43: 40-57.

30. Aksu B, Paradkar A, Matas M, Özer Ö, Güneri T, York P. A quality by design approach using artificial intelligence techniques to control the critical quality attributes of ramipril tablets manufactured by wet granulation. Pharm Dev Technol 2013; 18: 236-45.

31. Mesut B, Aksu B, Ozsoy Y. Design of sustained release tablet formulations of alfuzosin $\mathrm{HCl}$ by means of neuro-fuzzy logic. Lat Am J Pharm 2013; 32: 1288-97.

32. Aksu B, Aydoğan M, Kanik B, Aksoy E. A flexible regulatory approach for different raw materials suppliers using QbD principles. Res J Pharm Biol Chem Sci 2013; 4: 358-72.

33. Aksu B, Gokce EH, Rencber S, Ozyazici M. Optimization of solid lipid nanoparticles using Gene Expression Programming (GEP). Lat Am J Pharm 2014; 33: 675-84.

34. Aksu B, Paradkar A, Matas M, Özer Ö, Güneri T, York P. Quality by design approach: application of artificial intelligence techniques of tablets manufactured by direct compression. Pharm Sci Tech 2012; 13: 1138-46.

35. Aksu B, Matas M, Cevher E, Özsoy Y, Güneri T, York P. Quality by design approach for tablet formulations containing spray coated ramipril by using artificial intelligence techniques. Int $\mathrm{J}$ Drug Deliv 2012; 4: 59-69.

36. Demir Ö, Aksu B, Özsoy Y. Araştırma-geliştirme çalışmalarında tasarımla kalite yaklaşımı ve yapay sinir ağı modellemesinin önemi. Türkiye Klinikleri J Pharm Sci 2015; 4: 17-36. 